\title{
Article
}

\section{The Staged Competition Innovation Theory}

\author{
Christopher A. Jensen
}

Citation: Jensen, C.A. The Staged Competition Innovation Theory. J. Open Innov. Technol. Mark. Complex. 2021, 7, 201. https://doi.org/ 10.3390/joitmc7030201

Received: 4 August 2021

Accepted: 7 September 2021

Published: 10 September 2021

Publisher's Note: MDPI stays neutral with regard to jurisdictional claims in published maps and institutional affiliations.

Copyright: (C) 2021 by the author. Licensee MDPI, Basel, Switzerland. This article is an open access article distributed under the terms and conditions of the Creative Commons Attribution (CC BY) license (https:/ / creativecommons.org/licenses/by/ $4.0 /)$.
Faculty of Architecture Building and Planning, University of Melbourne, Melbourne, VIC 3010, Australia; cjensen@unimelb.edu.au

\begin{abstract}
Innovation is critical to technological progress and has many theories to explain its processes. Organised competition has been shown empirically to provide an alternative pathway for innovation within an industry, increasing innovation rates and radicalness. This research introduces and develops the new staged competition innovation theory which builds on the well-understood diffusion of innovation theory and the Technology-Organisation-Environment framework to explain how decision-making and technological, organisational, and environmental characteristics of industry-based competition can drive innovation activity. The new theory comprises three principles that demonstrate how a well-designed staged competition provides: (1) a unique innovation mechanism away from parent industry constraints, (2) a unique agile environment that can increase innovation development, and (3) a return pathway for adoption back to the parent industry. Principle 2 addresses the specific competition environment criteria required to drive innovation, beginning with a co-dependency between organiser and teams in providing team confidence and a mutually beneficial outcome for both parties. Relative advantage drives teams to innovate by generating competitive pressure, while a variable solution space due to competition specific rules and competition brief clarity direct innovation efforts. Finally, competition repetition provides ongoing innovation transfer between teams within the competition and to the parent industry.
\end{abstract}

Keywords: innovation; competition; staged competition; innovation adoption; competition environment

\section{Introduction}

Innovation leads to macroeconomic growth, a concept first identified by Schumpeter [1], who defined the concept of "creative destruction" to describe the process by which new products replace old products. As a result, innovation has been a field of enquiry for decades since, with the majority of the research focusing on the manufacturing sector from which products arise [2], however the benefits of competition on innovation are not captured in existing theories, despite extensive empirical evidence.

\subsection{Innovation}

Invention, creativity, and innovation are particularly important for societal economic growth [3] and are commonly defined as being either radical or incremental [4], where incremental innovation refers to improvements within a given frame of solutions, that is, 'doing better what we already do', radical innovation is a change of frame, that is, 'doing what we did not do before' [5]. Radical innovations are characterised by their novelty, uniqueness, and degree of adoption [6] and have been described as the most powerful type of innovation [7]. Although unlikely to provide a single magic bullet, radical innovations may effect major change within an industry [8] and thus the opportunity to exploit such innovation is of particular interest. Potential sources of radical innovations have been defined in the literature as new entries (i.e., entrepreneurs and entrants from other markets), external shocks or crises (i.e., occasional events that lead to unorthodox experiments), new technology performance, market change and industry market competition [9]. 


\subsection{The Role of Competition}

The word competition is most easily defined as 'competing to win' a pre-set challenge. Market competition is the term given to free market economies in which 'firms compete to win customers' [10]. Market competition is well understood to influence innovation in industries [1]. However, market competition is not always beneficial to innovation for public good [11], and it is ultimately the markets' decisions that determine the fate of an individual innovation. In contrast, in staged competition, 'teams compete for a prize' in artificial repetitive events outside the parent industry regulations where market competition occurs. Such examples of existing staged competitions are diverse, including innovation contests, architectural design competitions and motorsport series, which contribute innovation activity that is less likely to occur in the parent industry due to inherent barriers. Staged competition is always governed by competition specific rules agreed on by the participants and a governing body. Importantly, staged competitions are based on predefined challenges that focus on the creation of relevant innovation generation, design, prototyping and, in some cases, adoption back into the parent industry. Staged competition allows the organiser to determine the direction of innovation effort with much greater freedom than is possible in the parent industry. Such ex ante prizes draw each teams creativity, imagination, and innovation in response to a specific real or artificially determined 'need'.

\section{Literature Review}

\subsection{Industry Use of Competition for Innovation}

A central theme in the literature is that technological innovation is enhanced by both market and nonmarket competition. Nonmarket competitions are referred to as industry- based global challenges [12], recognition prizes [13], innovation contests [14], or crowdsourcing [15]. Such open innovation competitions traditionally occur within the industry market environment constraints [16]. While such competitions often lack the physical dimension, they have been shown to be highly effective in the generation and promotion of ideas [17]. The benefits of these competitions include reaching a broad range of entrants, paying only for performance, leveraging outside resources, creating parallel innovation, and attracting public interest [18]. Competitions of this type can be one-off or repeated competitions, such as those used regularly by the United States government or the X-Prize Foundation, both of which tend to focus on developing technological prototypes in response to an industry challenge or unmet need. Ex post competitions, such as industry awards, also provide competition-style judging and rewarding but only indirectly influence innovation development, and instead focus on best practice and high achievement outcomes [19].

Kay [20] comprehensively investigated prize incentives, analysing how entrants respond to million-dollar prize incentives and organise research and development (R\&D) activities, and how technology advancement occurs in this context. Kay found there is a wide range of motivation for an entrant to participate, with non-monetary incentives being the greatest incentive, and noted the importance of entrants from outside the field, a feature that is unique to the competition environment. The author showed that R\&D efforts are affected by competition structure such as duration, collaboration, and simplicity, and that prize incentive approaches to R\&D can enable unorthodox approaches to be implemented but not easily anticipated. Technological outputs vary with the type of entrant, and incentives induce outputs at a higher maturity level but only if the challenge definitions are specific. Effects on innovation are determined by the prize incentive, gaps in technology, and definition of the challenge, including rule openness. Importantly, the study finds that these competitions can induce innovation over and above what would have occurred anyway, while breakthrough innovation can be enabled but not directly induced. This finding supports the need for a new theory. 


\subsection{Existing Theories of Innovation}

Existing theories related to technological innovation are diverse, and innovation processes are already well established for an industry environment. The key existing theories include the diffusion of innovations (DOI) theory (internal decision-making) and the technology-organisation-environment (TOE) framework (effect of external influences).

\subsubsection{The DOI Theory}

Roger's DOI theory addresses many aspects of innovation, and emphasises the generation (idea), diffusion (movement) and adoption (uptake) of innovations [21]. The 'innovation decision model' (IDM) can be used to explain how innovations proceed to adoption within an organisation in an industry environment. The five stages of the IDM are knowledge, persuasion, decision, implementation, and confirmation. Rogers also defined five perceived attributes of an innovation that help decrease uncertainty and increase adoption rates: (i) relative advantage, (ii) compatibility, (iii) complexity, (iv) trialability and (v) observability. Both the IDM and perceived attributes are relevant to successful innovation adoption within industry (see Figure 1).

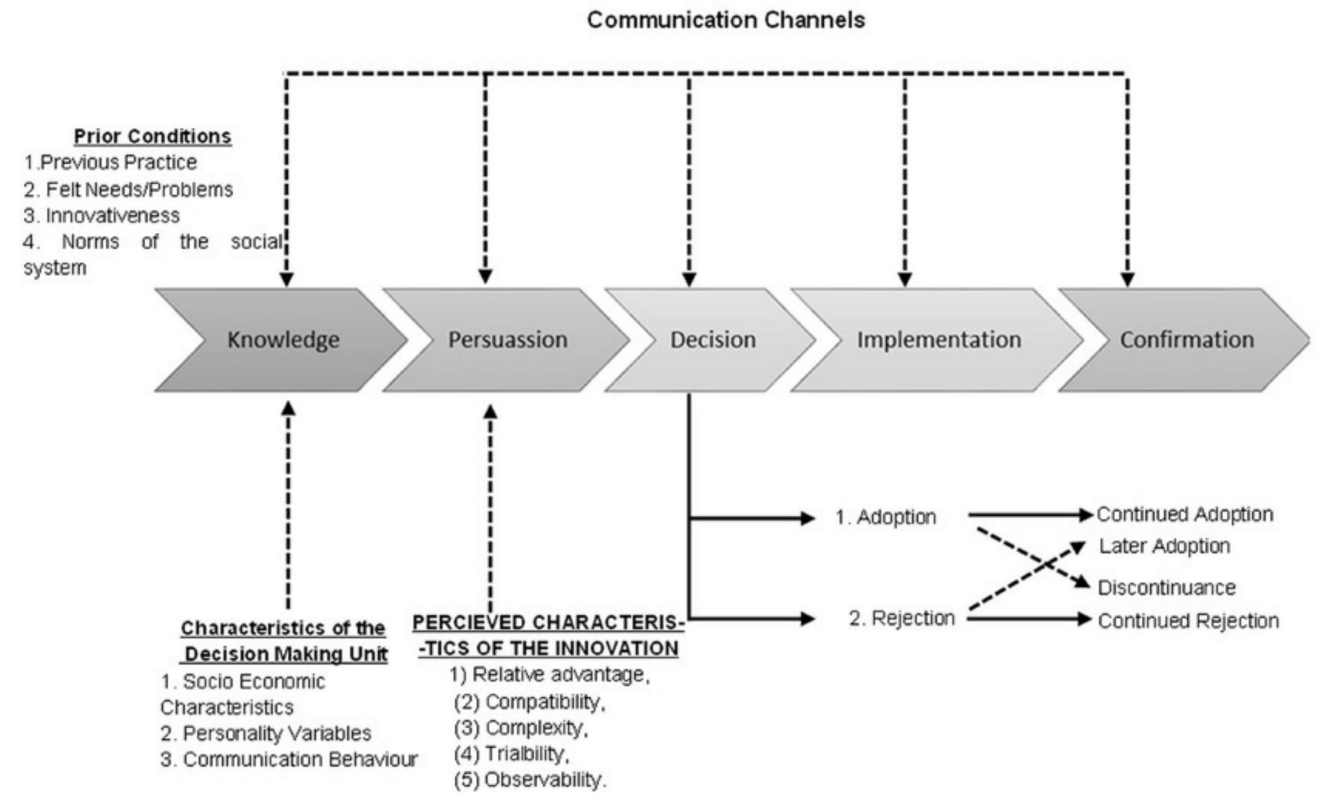

Figure 1. Diffusion of innovations' (DOI) innovation decision model (IDM).

\subsubsection{The TOE Framework}

While the DOI theory is primarily concerned with origins, movement and decisionmaking to progress an innovation from knowledge through to confirmation and adoption, the TOE framework (see Figure 2) considers the characteristics of the Technology, Organisation and Environment in the process of making a decision to adopt the innovation [22]. This framework is considered more complete than the DOI theory, as it includes the environmental context [23] and is suitable for framework development [24]. 


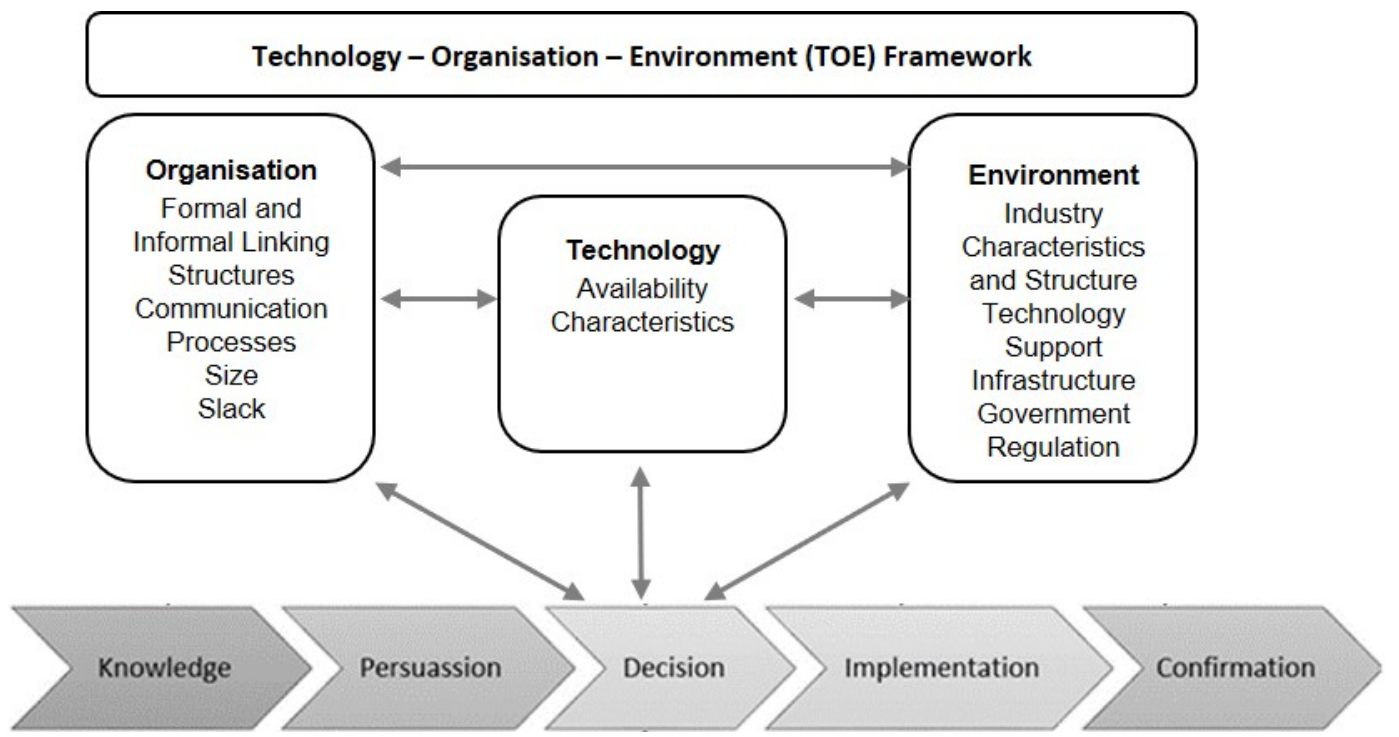

Figure 2. The TOE framework as originally defined by Tornatzky et al., (1990) [22].

\subsubsection{DOI and TOE Combined}

The DOI and TOE frameworks can be merged to describe innovation processes [25-27]. Alkhalil, Sahandi [28] found that the TOE framework helps in categorising determinants, while the DOI model helps in determining specific variables within each category. Arpaci, Yardimci [29] also supported combining these two theories to explain innovation adoption of information technology. Moreover, [30] demonstrated how the characteristics of the decision-maker [21] and TOE [22] work together to provide a complete explanation of the innovation process. Therefore, the two frameworks are complementary and can provide a better understanding of innovation adoption. However, despite the established theoretical understanding and strong empirical evidence of the value of innovation from staged competition, there is no central theory that describes innovation processes in competitive environments outside the industry market. Both competition and innovation are important in developing society and industry but have not adequately been addressed together. Because existing theories used to describe innovation processes do not address the unique competition environment, the opportunity to capitalise on the competition environment is lost in these overarching theories. A new theory is required.

\section{Methods}

\section{Use of Existing Theories}

The DOI theory's IDM [21,31] was used alongside the TOE theory [22] for case study analysis which is an appropriate method for testing or generating theories [32]. The longitudinal case study drew heavily on archival information to provide a detailed, historical case study from which to derive new insights into innovation processes by matching patterns in the data with theoretical explanations [33]. Eisenhardt [34] noted that this type of research permits comparisons between technological trajectories to determine patterns and understanding that would not be possible using more cross-sectional methods. Moreover, any fact relevant to the stream of events in a case study is a potential datum since context is important [35], and specialist periodicals available in this field offer a wealth of valuable knowledge [36]. Content analysis was used to collect data [37] on the rapid development of the turbocharger in motorsport, which was selected because of the significant amount of data available and relevance of the technology. Following data collection, innovation factors were grouped into TOE contextual themes as proposed by Baker [38] and Ruan, Hang [39]. Both industry and firm-level effects within the Formula 1 motor-sport series were investigated, in which innovation development was led by Renault, as an early 
adopter of the technology, and adoption was influenced by competition rule changes by the Fédération Internationale de l'Automobile (FIA).

\section{Case Analysis}

\subsection{Background}

Motorsport-A Model Competition

Motorsport is defined as the racing of vehicles, an activity nearly as old as automobiles themselves. Importantly, motorsport is unofficially separated into two distinct classes: prototype and production [40]. A prototype race series (e.g., Formula 1) does not require the use of vehicles that are based on road-going models, while a production race series (e.g., Rally or Le Mans GTE) is restricted to using vehicles based on a production car. Both classes are subject to the competition organiser's rules and regulations which differ between classes to restrict or allow technology development. Innovation benefits are found in both classes. A prototype competition is likely to advance the development of radical new technologies that are not usually applied to production vehicles, while a production competition tests existing technology (often resulting in incrementally innovative solutions). A production competition has more relevance to current technologies and methods and is more likely to be adopted by the parent industry in the short-term [41].

Automotive manufacturers take motorsport seriously concerning innovation development, testing, and the marketing and promotion of motorsport successes. There are many different types of competitions, such as on-road, off-road or circuit racing, and many vehicle types to accommodate the interests of most manufacturers. Arguably, the most renowned global motorsport events post-1970 include the prototype Formula 1 circuit race series, World Rally Championship (WRC) off-road production racing series, and the Le Mans endurance race series (which combines prototype and production classes). All three events present a different challenge to teams and are each heavily supported by major manufacturers. In the case of Formula 1, Ferrari, McLaren, Mercedes, Renault, Honda, and Toyota have been involved over a lengthy period. In the case of WRC, Volkswagen, Citroen, Subaru, Mitsubishi, and Peugeot have been regular entrants. Le Mans entrants have included Porsche, Ferrari, Audi, Toyota, Aston Martin, and Ford.

\subsection{The Turbocharging Gamble}

The introduction of the turbocharger to motorsport by Renault is an example of a new entrant with new technology displacing incumbents and is a transparent account of a competition-based innovation that was refined for adoption into production cars. Testing in the motorsport environment advanced the turbo technology and is now widely used for performance and regulatory benefits such as in the European Union to reduce engine sizes to limit $\mathrm{CO}_{2}$ emissions without loss of performance [42]. Renault experimented with the turbo in endurance racing (Le Mans), Rally, and Formula 1 concurrently during the 1970s [43]. This experimentation is reflected in the different engines Renault produced for each series that were experimentally turbocharged. As Formula 1 was the most sought-after trophy and, therefore, highly desirable, Renault focused most of its efforts on this series in the latter years of the 1970s. Since that time Renault has continued to consider Formula 1 as the most prestigious motorsport with substantial marketing benefits [44].

Originally introduced to Formula 1 by the FIA in 1966, the turbo displacement rule limited engine displacement, and was determined using a theoretical calculation of potential power from the engine with no allowance for weight savings, altitude racing, or other technology performance externalities. For 11 years (1966-1977), there were no turbocharged engine entries, as it was believed by the incumbent teams the power could not be achieved with such a small engine. Innovation by a new entrant proved successful and now represents an excellent example of an early disruptive innovation in motorsport $[45,46]$.

It took Renault three years to prove the success of their turbocharged combination in Formula 1, with the first GP win in 1979. Following this win, Ferrari and other manufacturers saw the competitive advantage of the turbo and developed engines to match or beat the 
Renault [47]. Ferrari, shown to be ambidextrous with innovation [48], introduced their new turbo engine swiftly for the 1981 season. As the turbo's performance benefits became clear, by 1983 more than half the field used turbocharged engines. From 1985, eight years after the initial introduction, every entrant in Formula 1 had a turbocharged car. In response to safety and cost concerns, the FIA progressively restricted turbo boost pressure to try to control the cars. In 1986, the FIA banned non-turbo engines, but overturned the ban in 1987 by implementing fuel maximums, eliminating pitstops and reducing rev counts and boost pressure before finally implementing a total ban of turbocharging due to safety concerns over the speeds being reached. Consequently, this exciting developmental period from 1977 to 1988 is described as the 'turbo era' in Formula 1 and highlights the relationship between motorsport innovation and competition rule changes.

Data for this study focuses on pole position rather than race wins, which would introduce a complex array of other factors such as unrelated mechanical failure. Beginning with the first Renault turbo car in 1977, it was not until 1982 that Renault demonstrated command of the technology, with 10 pole positions across the season. The high number of pole positions is supported by a low standard deviation, representing performance consistency (see Figure 3). Race finishes also increased from 0 percent to 43 percent across the six-year effort. Unfortunately, Renault was never able to take the Formula 1 constructors' championship during this time, despite leading the way with the innovative technology. Technology adoption by other teams (see Figure 4) was evident in Renault's pole position average, which slipped from three to nearly 12 in the following three years (1983-1985) (see Figure 3).

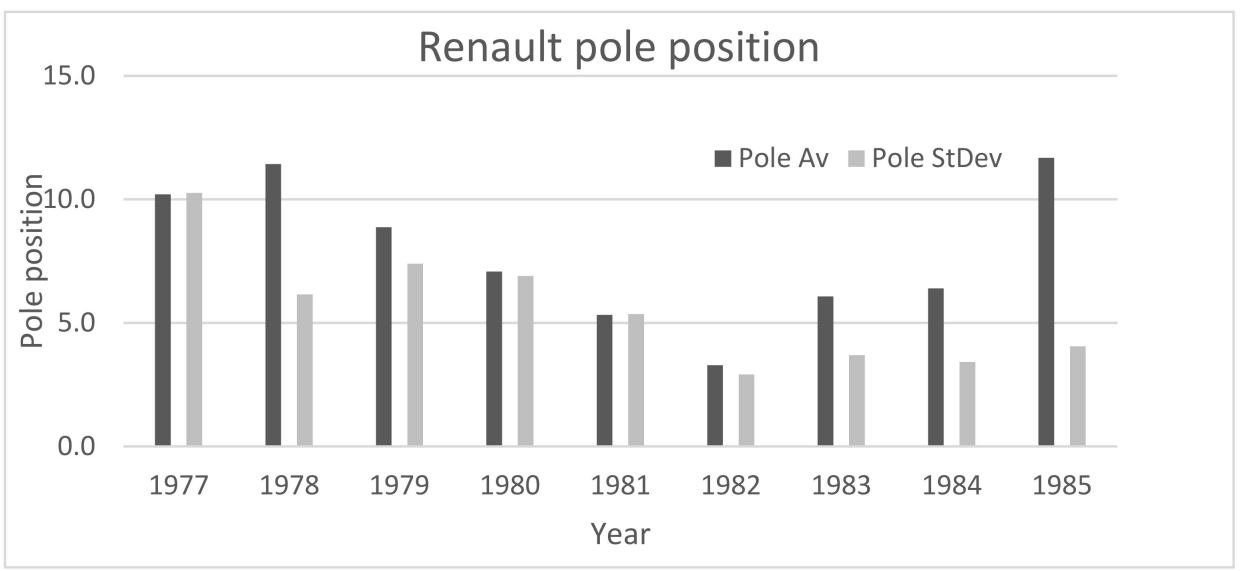

Figure 3. Renault pole position across turbo period.

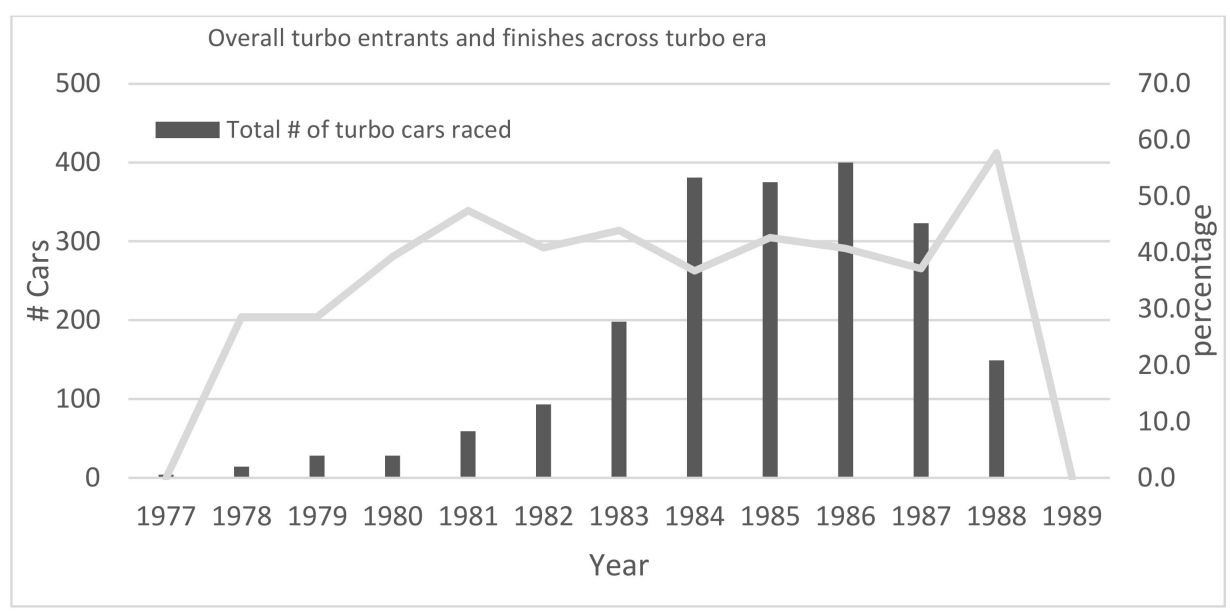

Figure 4. Turbo entrant starts and finishes across turbo period. 


\subsection{TOE Analysis}

This case study analysis used TOE critical factors compiled by [38] to identify relevant factors that influence innovation processes in a competition environment. These factors have been addressed according to the identified TOE categories.

\subsubsection{Technology}

TOE Factors: Opportunity, Technological Readiness, Compatibility

Regardless of technological readiness level, innovations ultimately must demonstrate compliance with parent industry regulations to prove the compatibility of the innovation. Compliance can take many years in the parent industry. The competition environment provides an opportunity to demonstrate compatibility of innovation without delay as seen in the turbo case. Compatibility between the innovation and real or staged 'needs' was found to be an important criterion. At the firm level, compatibility represents the ability of the innovation to meet the performance needs of the technology such as engine power, durability, weight, and organisational compatibility such as prior experience with the technology in other series. Although there was a degree of uncertainty, the turbo had high compatibility as a technology that had been used previously by Renault and worked with the internal desire to maintain smaller engine displacements. The turbo technology did not specifically represent compatibility with the FIA; but was allowed alongside normally aspirated engines for many years. As the turbo technology began to compromise the goals of the FIA, the technology was banned or restricted so that the FIA's interests were protected. At this time, lack of compatibility with the FIA's goals at the industry level conflicted with the technology's compatibility at the firm level. Therefore, agile regulations at the discretion of the FIA are a key driver of innovation development, providing an attractive opportunity to manufacturers who wish to progress their innovations outside the parent industry in a controlled environment.

\section{TOE Factor: Relative Advantage}

The staged competition environment of motorsport in the turbo era provides a clear goal for each team: overall car speed and reliability. Such a defined target within the competition environment emphasises small relative advantages for the teams. To benefit from this opportunity, Renault used their past experience with the turbo from other race series to implement the turbo innovation in Formula 1. Once some technical difficulties were resolved, the benefits of a smaller turbocharged engine provided a relative advantage to Renault, leading to pole positions and, eventually, race wins. This led to the diffusion and adoption of the turbo across the entire competition field, as well as into the parent industry. As the rules tightened over time, it became more difficult for teams to gain a relative advantage from the reducing solution space available, leading to more competitive racing. The focused rules provide a specific direction for innovation by the organiser, and the regulator's ability to make such a defining decision so quickly is an attribute of the competition environment that is unseen in the parent industry environment.

\section{TOE Factors: Observability, Trialability}

There is limited opportunity for trialability and observability in the parent environment beyond internal R\&D and testing processes. The staged competition environment provides an opportunity for a team to test a prototype and make continual improvements at a faster rate due to event frequency and repetition within the competition series. Ongoing testing of innovation in the cars is then fully trialled at the next event against the competitor teams, allowing continual feedback on performance. The trialability of innovation in the staged competition environment were evidently beneficial to Renault, where the alternating period of experimentation (development) and competition (testing) accelerated the innovation process. The competition environment also provided opportunity for observability and, consequently, diffusion of technology between teams. Observability and trialability that results from repetitive competitions evidently increases the rate of 
innovation development and diffusion within the competition environment. Therefore, event repetition represents a significant difference in the usual processes of technological innovation that occur in the industry. In these circumstances, an innovation undergoes internal testing prior to approval for sale.

\section{TOE Factor: Relevance}

The perceived relevance of innovation to the parent industry is critical to its final adoption. A prototype competition like Formula 1 is unlikely to provide an opportunity for direct innovation adoption to production cars. However, such prototype innovation is diffused to other teams and other racing series such as rally and Le Mans and is then refined for adoption into production cars. Competition relevance was a key factor for Renault in their participation in numerous motorsport classes, and they proudly proclaim their use of Formula 1 technology in their high-end road vehicles.

\subsubsection{Organisation}

The following TOE criteria have been identified as important for the organisational aspects that influence the processes of technological innovation in the competition environment.

\section{TOE Factors: Leadership, Top Management Support, Size}

Like most competition organisers, the FIA is independent of other organisations including government agencies. Instead, the regulations are determined in part by committee in conjunction with race team representatives, as changes affect innovation direction, financial decisions for teams, and race procedures. Compared with the rigidity of the parent industry, such independence and leadership can also be used to improve competitive balance between teams [49]. Seasonal rule changes are more likely to be introduced and be comprehensive when a team has been dominant in the previous season. For example, [49] have shown that a unit increase in the standard deviation of points scored by the teams in a Formula 1 season significantly raises the expected number of rule changes in the next season by about 3 per cent. There are many reasons to modify the rules, often for the benefit of the teams (e.g., cost, safety, and fairness) or of racing (e.g., close racing and excitement). The response of the FIA to team dominance is usually to attempt to create competitive balance, as close competition increases race excitement and viewer interest. Such a role in directing the competition environment represents both leadership in innovation by the organiser and a supporting role to the teams. The independence of the FIA to make agile decisions without any external or higher-level approvals is unique to the competition environment and is unseen in the parent industry. The independence and decision-making required to accommodate such agile regulations requires the leadership of both the FIA and teams.

\section{TOE Factors: Collaboration}

The goal of the FIA to maintain competitive balance conflict with individual team goals that aim to win as many races as possible at any cost, often through exploitation of the competition rules [50]. An example of such exploitation to win was characteristic of the aerodynamic 'ground effect' innovation in the 1970s. Like the turbo example, teams quickly adapted to the major potential performance benefits that could be gained through this innovation, and shortly thereafter rules were modified by the FIA and team representatives to maintain competitive balance. The collaboration of the organiser and teams to balance the need for competitive balance with need for each team to achieve individual wins demonstrates the co-dependency that is unseen in the parent industry, in which firms pursue their own individual success (e.g., financial) and the industry regulator has no role in ensuring equity of the regulations to maintain competitive balance. 
TOE Factors: Innovativeness, Prior Experience

The importance of innovativeness and prior experience of a team highlights how a large solution space affects innovation radicalness. The size of the solution space, defined by the strictness of the competition rules, is determined by the organiser to achieve the goals of the competition. A small solution space is likely to provide incremental innovation as opportunities are limited, and technology adoption will converge between teams. If the goal of a competition is to generate radical innovation, the rulemaking should be limited to overall top-down targets, resulting in a large solution space as is evident in the turbo example. The size of the solution space determines the potential for radical innovation.

\section{TOE Factors: Financial Resources}

Renault was well prepared for the introduction of the turbo into the Formula 1 competition environment due to their innovative culture, prior experience with the technology and significant external financial support from Elf Aquitaine [51]. For a period, Elf Aquitaine and Renault were co-owned by the French government, and a long-term partnership was developed. Without these external financial resources, Renault quite likely would not have been involved in motorsport. The financial resources of a team represent their potential for involvement and innovation capability within the competition environment.

\subsubsection{Environment}

The following TOE criteria have been identified as important for the environmental aspects that influence technological innovation processes in the competition environment.

TOE Factors: Industry Structure, Innovation Opportunity, Agile Regulations

The competition environment is a subset of the parent industry environment but with its own unique operating conditions and rules. Opportunity, through agile regulations, is critically important to attracting firms to form teams to participate, and continuous participation is achieved by providing a stable environment to provide confidence to teams to continue. [52] suggested that peaks and troughs of markets are perceived as uncertain and firms prefer to invest in innovative technology in intermediate points, which are perceived to be more stable. Careful design of the competition environment is critical to the overall success of the competition.

\section{TOE Factors: Competitive Pressure}

Competitive pressure occurs in competition because many teams innovate to achieve the same outcome within a given timeframe. Moreover, the repetition of the competition also drives competitive pressure across multiple events, leading to an ongoing increased innovation rate. Modern Formula 1 rules are specifically designed to increase competitive pressure through the control of the focused task targeted by a number of teams in an ongoing series [49]. In the case study example, the success of the turbo created a new competitive pressure that was felt by the other teams. Conversely, Renault would have experienced competitive pressure from its rival teams to prove the technology. The effect of this competitive pressure would also have contributed to the increased rate of innovation by Renault and other teams.

\section{TOE Factors: Solution Space}

During the turbo era, the FIA provided a large solution space that benefited teams when compared with the constrained parent industry environment, a strategy that allowed for radical innovation and a measured pace of adoption [38]. Innovation progress was halted by the actions of the FIA across the turbo period as a result of the progressive tightening of the rules and subsequent reduction in solution space. Although the bans were due to safety, costs, or for competitive balance [53], the lost technological development also comes at price previously ignored, as banned technology is not further developed in motorsport and less likely to be adopted by the parent industry. In the case of the turbo, 
there was enough awareness in the parent industry that it continued to be used despite the Formula 1 ban. This analysis provided evidence of the importance of the solution space size to the organiser as well as the teams.

\section{TOE Factors: Repetition}

Innovation observability and trialability that provides benefits from competition is attributable to repetition. A competition series with multiple events results in alternating $R \& D$ periods and race events, the latter acting as the testing phase. This contrasts with the normal market-based industry in which R\&D is continuous, and private testing is held as required without any visibility by other firms or the public. The benefit of high event repetition is to accelerate both the $R \& D$ process (to be ready for the next event) and to increase the trialability and observability (testing) of the innovation, leading to a higher innovation rate. To illustrate this from the case study, Renault developed approximately one new engine per calendar year, significantly more than the number developed for production vehicles which were produced in much greater numbers. Therefore, event repetition is critical to the rate of innovation, both for the individual team innovating through increased trialability and for the other teams through increased observability.

\section{External Benefits to Competition}

The motorsport case study shows how the staged competition environment contributes to the innovation potential resulting from competition. However, there is also potential financial benefit to teams that participate, which can be described in two ways:

- Direct R\&D benefit to firm, in which innovations are tested and brought to market for financial gain through use in production cars.

- Marketing benefits, which are proven to be a powerful strategy for firms to market their product based on the success of their prototypes in a competition environment. This strategy is so powerful that Formula 1 has non-automotive race teams, such as Red Bull, that compete with no automotive innovation benefits.

Although marketing benefits are not addressed in this study, considerable evidence exists to show it is a major driver of competition participation.

\subsubsection{TOE Analysis to Create the Staged Competition Innovation Theory}

Table 1 shows the TOE factors used in this case study analysis to derive the staged competition innovation (SCI) theory.

Table 1. TOE factors used in developing the SCI theory.

\begin{tabular}{|c|c|c|c|c|c|c|}
\hline \multirow[b]{2}{*}{ Factor } & \multirow{2}{*}{$\begin{array}{l}\text { Principle 1: Incentive to } \\
\text { Innovate }\end{array}$} & \multicolumn{4}{|c|}{ Principle 2: The Competition Environment } & \multirow{2}{*}{$\begin{array}{l}\begin{array}{c}\text { Principle 3: } \\
\text { Adoption } \\
\text { Pathway }\end{array} \\
\text { 3. } \\
\text { Adoption }\end{array}$} \\
\hline & & $\begin{array}{l}\text { 2a. Co- } \\
\text { Dependence }\end{array}$ & $\begin{array}{l}\text { 2b. Relative } \\
\text { Advantage }\end{array}$ & $\begin{array}{l}\text { 2c. Dynamic } \\
\text { Rules }\end{array}$ & $\begin{array}{l}\text { 2d. Competition } \\
\text { Frequency }\end{array}$ & \\
\hline Technology & $\begin{array}{l}\text { Opportunity } \\
\text { Technological readiness } \\
\text { Compatibility }\end{array}$ & - & $\begin{array}{l}\text { Relative } \\
\text { advantage }\end{array}$ & - & $\begin{array}{l}\text { Observability } \\
\text { Trialability }\end{array}$ & Relevance \\
\hline Organisational & $\begin{array}{l}\text { Leadership } \\
\text { Top management support } \\
\text { Size }\end{array}$ & Collaboration & - & $\begin{array}{l}\text { Prior } \\
\text { experience } \\
\text { Innovativeness }\end{array}$ & - & $\begin{array}{l}\text { Financial } \\
\text { resources }\end{array}$ \\
\hline Environmental & $\begin{array}{l}\text { Industry structure } \\
\text { Innovation opportunity } \\
\text { Dynamic regulatory } \\
\text { environment }\end{array}$ & - & $\begin{array}{l}\text { Competitive } \\
\text { pressure }\end{array}$ & $\begin{array}{l}\text { Large solution } \\
\text { space }\end{array}$ & Repetition & $\begin{array}{l}\text { Market } \\
\text { pressure * } \\
\text { Supplier } \\
\text { support* }\end{array}$ \\
\hline
\end{tabular}

* Factors are a feature of the parent industry environment. 


\section{The SCI Theory}

The staged competition innovation (SCI) theory is a new theory that expands on existing theories to explain innovation processes in a competition environment. This has been achieved by mapping the TOE criteria factors determined to be relevant to innovation processes in the motorsport case study. Three principles describe the benefit of the competition environment to innovation processes: a new mechanism, a unique environment, and a pathway to adoption (see Figure 5).

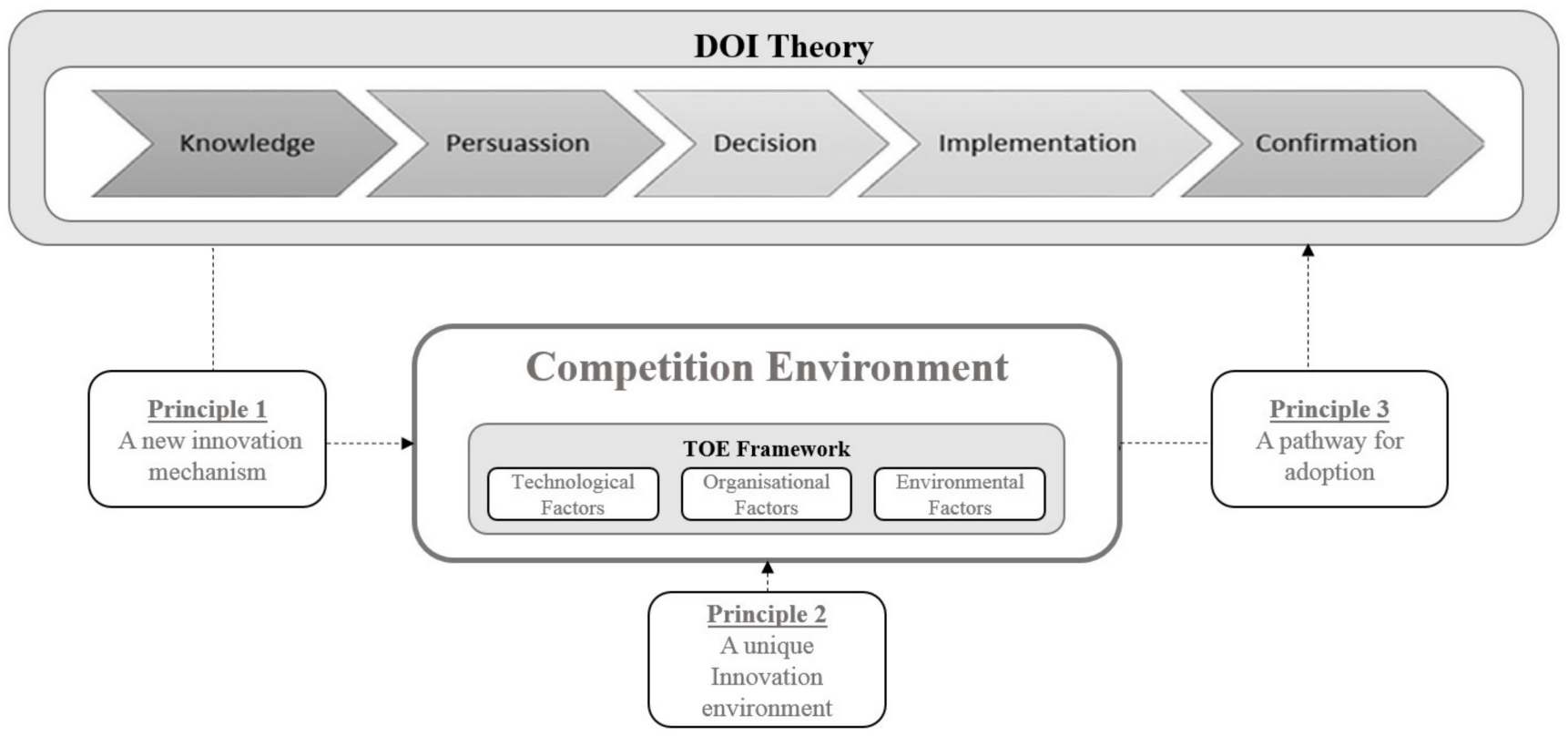

Figure 5. The three principles of SCI theory with existing innovation theories.

\subsection{Principle One-A New Innovation Mechanism}

The purpose of the competition environment is to address an innovation need or challenge that cannot be addressed in industry. The competition environment can be custom-made to encourage and enable innovation, providing incentive and urgency to the innovation process. The motorsport case study demonstrates how one team innovated to achieve the competition goal of outright vehicle speed; a need that has no relevance in the parent industry (due to speed limits). However, the same competition platform provides a new development pathway that can be designed to be of benefit to the parent industry.

Leadership from an industry organisation is required to start a competition, which should address a need or challenge either because of market failure or an unmet public need. Competitions can target generation to address a new need, prototyping to address development or adoption to address diffusion and use. Generation competitions provide new ideas, designs or concepts. A prototype competition is of most benefit to teams advancing the innovation through R\&D, testing and trailing. Prototyping competitions are often aligned to a technological readiness level scale that is consistent with industry, although this is not a requirement [20]. Although adoption competition is the least common form of staged competition in both practice and in the literature, such competitions assist in innovation development in the commercialisation phase, and can include commercialisation support, awareness raising or innovation implementation, with focus on the perceived relevance of the innovation to industry or client needs, including factors such as the scale of production, promotion, and price.

\subsection{Principle Two-The Unique Competition Environment}

Once an innovation need is defined and a competition established, the competition environment becomes critical to the successful development of an innovation outcome and 
requires careful design. For example, an overly complex task that has little reward will be unlikely to attract entrants, resulting in little or no innovation effort. Key considerations include co-dependence, relative advantage through competitive pressure, dynamic rules, and competition frequency.

\subsubsection{Co-Dependence}

Co-dependence between the teams and the industry organiser is a requirement for the success of industry competition to drive mutually beneficial outcomes in innovation, ultimately leading to ongoing participation. This co-dependency contrasts with the parent industry in which the two equivalent groups (i.e., industry regulator and firms) act independently of each other. Co-dependency leads to collaboration, which is a beneficial outcome for a public good innovation outcome. Continuity of teams and organiser in a repetitive competition also results in advancement of innovation knowledge across time, which is otherwise missing from one-off innovation contests.

\subsubsection{Competitive Pressure}

Competitive pressure within the competition environment provides a greater relative advantage of an innovation than in the parent industry. This is because the technology contributes directly to the single-focused goal of the competition. Competitive pressure forces competitors to compare their own innovations, resulting in even a slight relative advantage being magnified. This encourages teams to make and benefit from even small innovations to achieve a relative advantage.

\subsubsection{Dynamic Rules}

A competition with few rules targeting a single goal (e.g., first to finish) provides an innovation environment characterised by a large solution space and radical innovation. Conversely, a competition defined by very prescriptive requirements, often including particular solution criteria, supports an innovation environment characterised by a small solution space, resulting in incremental innovation. The ability to design the rules and vary them to suit the outcome is unique to the competition environment. A small solution space is a natural feature of industries due to the restrictive regulations and cost constraints that reduce innovation radicalness.

\subsubsection{Competition Frequency}

Competition repetition provides increased trialability and observability resulting in greater experimentation, increasing the rate at which innovation occurs. Higher competition frequency creates inter-ream visibility of the innovation. Event repetition also influences the competition's marketability and attraction of sponsorship and public viewers.

These four fundamental criteria-co-dependence, competitive pressure, dynamic rules and competition frequency-explain how the competition environment increases innovation, with faster innovation progression and more radical outcomes.

\subsection{Principle Three-Competition as a Pathway to Mainstream Adoption}

The normal pathway to adoption for an innovation is already well defined by the DOI theory's IDM, noting that adoption is a function of compatibility, among other factors. Innovation generated in competition responds to specific criteria and is not always directly compatible with industry regulations, costs, and other constraints. However, adoption can be encouraged by modifying the competition rules such that the innovation is more relevant to the industry for adoption. This can be achieved through a smaller solution space and more incremental innovation that targets industry requirements. Motorsport addresses this problem through the different classes, focussing on the production classes for incremental innovation with industry relevance. Relevance, along with compatibility are required for adoption within the parent industry. Irrespective of direct relevance, a competition provides pre-qualification of an innovation through the process of winning the 
competition, as it is demonstrated to be the best out of a group of similar innovations under the competition's conditions. Such pre-qualification can lead to desirability independent of relevance, such as 'race-car' features on production cars. Winning a competition, subject to its quality and reputation, indicates to the market that this innovation has demonstrated a relative advantage compared with other similar innovations when assessed against very specific criteria. As the industry relevance criterion is restrictive to the solution space and radicalness of the competition, the multi-dimensional 'classes' of innovation development, as in the motorsport environment, proves to be a potentially valuable process to innovation progress into the parent industry.

The three principles outlined above have been defined to explain the new mechanism, unique competition environment and pathway for innovation adoption to occur that enables a higher rate and more radical innovation. These components together create the SCI theory (see Table 2).

Table 2. Principles of the SCI theory.

Three Principles of the Staged Competition Innovation Theory
PRINCIPLE 1-Competition provides a new mechanism for innovation.
1. Agile rules provide an opportunity for firms to compete in a unique environment to
test and prove their innovations
PRINCIPLE 2-Competition provides a unique innovation environment
2a. Co-dependency between teams and organisers drives mutually beneficial outcomes
in innovation, with both parties pushing for innovation success
2b. Increased competitive pressure for teams through a focused task drives innovation
development and testing
2c. Dynamic rules allow creative innovation solutions, leading to radical outcomes
2d. Competition frequency provides increased trialability and observability, increasing
the rate of innovation

PRINCIPLE 3-Competition provides an adoption pathway

3. Relevance and compatibility is critical for innovation adoption by the parent industry

\section{Discussion}

\subsection{The Need for New Theory}

The existing literature does not attempt to overlap innovation theories such as the well-established DOI theory [31] and TOE framework [22] with the unique competition environment. Thus, a need is created for knowledge of how a competition environment in an industry setting can drive innovation. This is attributable to the fact that competition is a relatively niche source of innovation within industry, and the mechanisms that drive innovation processes are overwhelmingly a product of the industry environment. The new SCI theory defined in this research adds a new perspective to the knowledge of innovation processes in industry, providing an understanding of the mechanism for innovation through competition. Importantly, the SCI theory defines the competition environment as a modified version of the parent industry environment; with the right competition design, a staged competition is purpose-built to increase innovation in the parent industry. Figure 6 illustrates how the SCI theory is a subset of existing innovation theories, corresponding with the competition environment as a subset of the parent industry environment. Identifying this gap and subsequent SCI theory development allows a detailed understanding of innovation processes from the competition environment and, more importantly, how this environment can be designed to achieve an increased rate and radicalness of targeted innovation. 


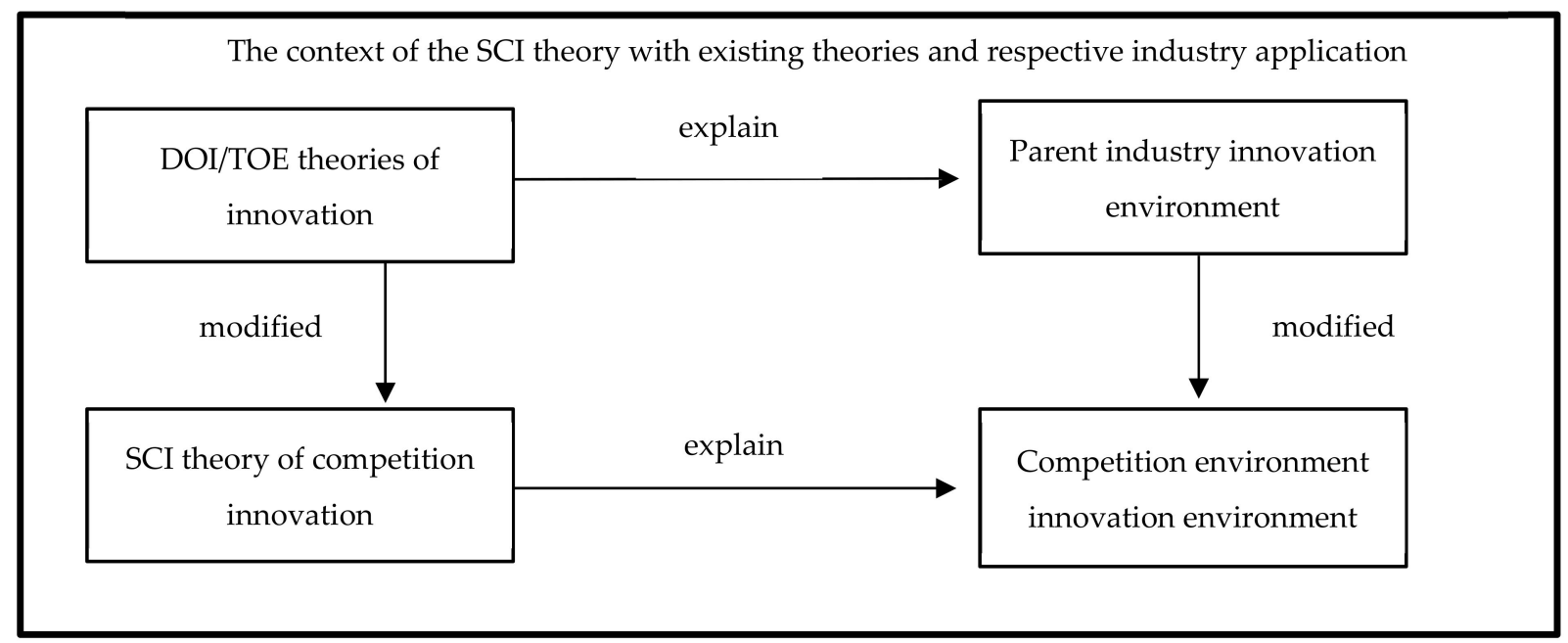

Figure 6. Revisiting the context of the SCI theory.

\subsection{Application to Applied Research}

Aside from the limited literature on innovation from motorsport, applied research into prize-incentivised innovation challenges is limited to a one-off prize-incentivised competition mechanism and the crowdsourcing opportunities provided by the internet. The existing research into industry competitions beyond motorsport focuses on macroeconomic influences [13]. These competitions operate at the ideas generation and prototype stage, with low repetition and limited address of adoption, public good challenges, and industry needs. Despite the scale and prestige of some of the prize series (e.g., X-Prize series), none of the existing research attempts to address the potential benefits that accrue from serial competitions that progress innovation from ideas to prototypes to adoption over a number of competitions held across time. Further, to date, existing research into such competitions does not acknowledge the significant value of the competition environment and its ability to address industry-level needs and challenges, such as safety, productivity, or greenhouse gas emissions, despite clear benefits of this type. Fortunately, the available literature in motorsport provides a clear illustration of the strength of the relationship and innovation exchange between the motorsport environment and the parent automotive industry, which is a universally accepted feature of the relationship [54]. The consistency of an independent overarching organiser and a repetitive competition series that targets focused innovation that has high relevance to the firms from industry that participate is seen to be a winning formula.

Where existing applied research is focused on the value and drivers of industry competition primarily at the individual or team level, this research is unique, as it focuses on the benefit of the competition environment to the parent industry. Moreover, it demonstrates how an innovation-focused competition can benefit the parent industry by providing an alternative pathway for innovation, starting with leadership from a single industry-based organisation to address a need or challenge that is relevant to potential teams who receive a benefit from participation. This research is also unique in its focus on a competition as part of a competition series, in which the innovation efforts are continuous and under the direction of the organiser. Of importance is the fragmentation of the industry and lack of an overarching body that addresses innovation goals and unmet needs at the industry level. The analysis of this case also provides a clear discrepancy between the comparatively large solution space of competition and the comparatively small solution space provided within industry. This difference is a direct result of the barriers identified in industry that do not necessarily apply in competition. Of relevance to industry policymakers, the research presented here confirms that the modified competition environment can progress innovation that is in a state of market failure due to well-established industry barriers, such as inability to recognise a need, barriers to production of a prototype and barriers 
to innovation adoption by industry. This flexible environment allows the competition to explore innovative solutions that would not be economically feasible in the parent industry and provide feedback into the existing regulation based on the specific demands of the competition. The flexibility in the competition environment as an innovation mechanism can be applied in industry like other drivers (e.g., financial incentives or regulation) to direct innovation efforts.

\subsection{Industry Benefits of Competitions for Innovation}

Safety and environmental concerns are good examples of industry challenges that require coordination across projects, governments, policies, and firms, and are unlikely to be comprehensively addressed at the firm level in the absence of an incentive. The current industry response to such challenges is to cautiously implement regulation to address such issues without harming the financial viability of the firms within the industry, as is evident in the automotive industry [55]. In contrast, motorsport, specifically Formula 1, has been used as a platform for many years to rapidly respond to safety issues from the perspective of drivers, cars and road environments [48]. The innovations from within the Formula 1 competition environment to address these issues result in outcomes that are mutually beneficial and highly relevant to the industry and firms and, therefore, readily adopted. These outcomes are identified in this research as Principle 2a, co-dependence, and Principle 3 , adoption. Such leadership to acknowledge the potential of the competition mechanism as a valuable pathway for innovation will establish a co-dependence and result in greater uptake of the mechanism to drive innovation.

The example of safety innovation in the context of the new SCI theory demonstrates the value of the flexible competition environment (Principle 2), which can operate independently of the parent industry to achieve innovation goals. Competition targets are most likely to stretch beyond the needs of the parent industry, for example, passenger vehicle safety requirements created by industry are not applicable to Formula 1 race cars, yet competition-specific safety criteria address the more demanding safety issues in the higher performance environment. Therefore, creating a focused task (e.g., high-speed cars) in the Formula 1 competition environment has, through competition rule changes, resulted in the by-product requirement of teams to address driver safety at high speed. Consequently, safety innovations from the focused Formula 1 task have been adopted by the parent industry into production vehicles, such as Formula 1-derived safety innovations like body shell construction, which is then advertised for its leading safety features to consumers, providing a clear demonstration of relevance to the parent industry.

This is how the competition environment encourages innovation with a rate and radicalness of innovation beyond what is possible in the parent industry. Competition creates a demand for innovation that does not exist in the parent industry. Competition to achieve such innovation is only possible if the competition rules are structured to bypass the same barriers that originally prevented the innovation. The right competition environment can result in assembly of special teams and can encourage the provision of time and financial resources to the competition. The mechanics at Renault do not have the time to dedicate efforts towards high performance, lightweight engines, as it is not required in the automotive industry. However, a demand is created, and such innovation is achieved by creating and resourcing the Renault Sport Formula 1 team.

The success of the incentive to team participation is based on how the teams perceive the value of the competition outcomes such as innovation commercialisation, recognition, or prize money. The Formula 1 competition has evolved to the point that the marketing benefits of participation outweigh the value of the technological innovation development opportunity. A competition that is highly valued by firms within industry is one that has significant industry support, as is evident in the Formula 1 example, in which the parent industry recognises the value of the original need or challenge identified by the organiser. From the team's perspective, the perceived value of the competition will initially relate to the potential for commercialisation and sales (assuming they are also a firm from the parent industry). This 
perceived value of a competition is also evident in the use of the Formula 1 competition by road car manufacturers as a platform for innovation development and marketability.

\subsection{Staged Competition and Open Innovation}

Open innovation has been a well-established and thoroughly researched topic since 2003 [56]. The competition-based variants [12-14] have many shared characteristics [57] with staged competition, most notably the closed process but open outcome format [58] and the prior arranged, time limited process of sourcing ideas from external sources as well as internal ones [59]. Both broaden the early-stage creativity process and derive benefits from shared R\&D. In the case of stage competition, participation is often open to the public providing few barriers but with large potential benefits. This is in contrast to barriers that small firms and start-ups are challenged with in open innovation [60]. Both formats combine the organisational strengths of participants and set challenges or needs that might otherwise be unmet, although stage competition is practically limited to technological or product innovation unlike open innovation strategies [61].

The key difference between staged competition and open innovation competitions is the role of the competition environment itself, the importance of the independent competition organizer operating at the industry level [62] and the repetition of events to increase the rate and radicalness of innovation. In contrast, open innovation remains anchored within the constraints of the industry environment with a focus on organisational culture, entrepreneurship [63] and the imperative to organize innovation. Where open innovation provides a new process for improved outcomes, staged competition provides a new tool to innovate outside the industry constraints.

\section{Conclusions}

This research introduces a new theory to describe innovation that occurs in nonmarket competition and explains the role of the competition environment as a tool for increasing the rate and radicalness of innovation. In contrast, the theoretical framework on which this research is based is taken from a parent industry market environment, based on well understood processes and barriers that drive and restrict innovation, with a focus on economic development as an end goal. Case study assessment using existing theories of technological innovation has been used to create a new theory that explains innovation through competition. The new theory comprises three principles that demonstrate how a well-designed staged competition provides: (1) a unique innovation mechanism away from parent industry constraints, (2) a unique agile environment that can increase innovation development, and (3) a return pathway for adoption back to the parent industry. This theory provides both theoretical knowledge by contributing to the understanding of innovation processes, as well as practical knowledge through establishing key principles that lead to innovation in competition. Importantly, it has been identified that a competition environment may be easily modified to address the innovation goals of the competition organiser and also the parent industry.

\subsection{Implications}

The staged competition innovation (SCI) theory can be used by individuals and organisations seeking to increase innovation where it is currently restricted within the normal market. The relevance of the adaptable competition environment to the needs of the innovation means that highly specific outcomes can be targeted in a way not otherwise possible. This theory will assist with competition design and can be used in theory by any industry.

\subsection{Limits and Future Research Topics}

The outcomes of an exploratory research project often result in more questions unanswered than originally asked, and that is proven to be the case here. Limitations of this research include the lack of quantitative data from innovation processes within competitions, and the lack of practical application primarily related to the lack of applied research. 
Further practical research would benefit the detailed development of the theory and model, specifically the key principles defined by SCI theory that describe the processes of innovation in a competition environment. The role of teams in a competition environment is also clearly an area in which more detailed research is required. Finally, further research is required in measuring the impact of a competition on the rate and radicalness of innovation, neither of which has been qualified in this research.

Funding: This research received no external funding.

Institutional Review Board Statement: Not applicable.

Informed Consent Statement: Not applicable.

Data Availability Statement: Not applicable.

Conflicts of Interest: The author declares no conflict of interest.

\section{References}

1. Schumpeter, J.A. The Theory of Economic Development: An Inquiry into Profits, Capital, Credit, Interest, and the Business Cycle; Transaction Publishers: Piscataway Township, NJ, USA, 1934; Volume 55.

2. Tushman, M.; Moore, W.L. Readings in the Management of Innovation; Ballinger Publishing Co.: Pensacola, FL, USA, 1988.

3. Rosenberg, N. Technology and American Economic Growth. M. E. Sharpe, Inc.: New York, NY, USA, 1972.

4. Garcia, R.; Calantone, R. A critical look at technological innovation typology and innovativeness terminology: A literature review. J. Prod. Innov. Manag. 2002, 19, 110-132. [CrossRef]

5. Norman, D.A.; Verganti, R. Incremental and radical innovation: Design research vs. technology and meaning change. Des. Issues 2014, 30, 78-96. [CrossRef]

6. Dahlin, K.B.; Behrens, D.M. When is an invention really radical? Defining and measuring technological radicalness. Res. Policy 2005, 34, 717-737. [CrossRef]

7. Koskela, L.; Vrijhoef, R. Is the current theory of construction a hindrance to innovation? Build. Res. Inf. 2001, 29, 197-207. [CrossRef]

8. Grubb, M. Technology Innovation and Climate Change Policy: An overview of issues and options. Keio Econ. Stud. 2004, 41, 103.

9. Van den Hoed, R. Sources of radical technological innovation: The emergence of fuel cell technology in the automotive industry. J. Clean. Prod. 2007, 15, 1014-1021. [CrossRef]

10. Linton, J.D. De-babelizing the language of innovation. Technovation 2009, 29, 729-737. [CrossRef]

11. Davis, L.N. Should we consider alternative incentives for basic research? Patents vs. prizes. In Proceedings of the DRUID Summer Conference, Copenhagen, Denmark, 6-8 June 2002.

12. X-prize.org. What Is an X-Prize? Available online: http://www.xprize.org/about/what-is-an-xprize (accessed on 8 February 2017).

13. Stine, D.D. Federally Funded Innovation Inducement Prizes; Diane Publishing: Collingdale, PA, USA, 2009.

14. Kay, L. The effect of inducement prizes on innovation: Evidence from the Ansari XPrize and the Northrop Grumman Lunar lander challenge. RED Manag. 2011, 41, 360-377. [CrossRef]

15. Natalicchio, A.; Messeni Petruzzelli, A.; Garavelli, A.C. Innovation problems and search for solutions in crowdsourcing platformsA simulation approach. Technovation 2017, 64-65, 28-42. [CrossRef]

16. Chesbrough, H. Open Innovation Results: Going Beyond the Hype and Getting Down to Business; Oxford University Press: Oxford, UK, 2019.

17. Carvalho, A. In Search of Excellence-Innovation Contests to Foster Innovation and Entrepreneurship in Portugal. 2009. Available online: https://dspace.uevora.pt/rdpc/bitstream/10174/1721/1/Innovation\%20contests_ISPIM_2009.pdf (accessed on 6 September 2021).

18. Boons, F.; Montalvo, C.; Quist, J.; Wagner, M. Sustainable innovation, business models and economic performance: An overview. J. Clean. Prod. 2013, 45, 1-8. [CrossRef]

19. Khan, B.Z. Inventing prizes: A historical perspective on innovation awards and technology policy. Bus. Hist. Rev. 2015, 89, 631-660. [CrossRef]

20. Kay, L. Technological Innovation and Prize Incentives: The Google Lunar X Prize and Other Aerospace Competitions; Edward Elgar Publishing: Cheltenham, UK, 2012.

21. Rogers, E.M. Diffusion of innovations. The Free Press: New York, NY, USA, 1995.

22. Tornatzky, L.G.; Fleischer, M.; Chakrabarti, A.K. Processes of Technological Innovation; Lexington Books: Lanham, MD, USA, 1990.

23. Oliveira, T.; Martins, M.F. Literature review of information technology adoption models at firm level. Electron. J. Inf. Syst. Eval. 2011, 14, 110-121.

24. Bosch-Rekveldt, M.; Jongkind, Y.; Mooi, H.; Bakker, H.; Verbraeck, A. Grasping project complexity in large engineering projects: The TOE (Technical, Organizational and Environmental) framework. Int. J. Proj. Manag. 2011, 29, 728-739. [CrossRef] 
25. Chong, A.Y.-L.; Lin, B.; Ooi, K.-B.; Raman, M. Factors affecting the adoption level of c-commerce: An empirical study. J. Comput. Inf. Syst. 2009, 50, 13-22.

26. Wang, Y.-M.; Wang, Y.-S.; Yang, Y.-F. Understanding the determinants of RFID adoption in the manufacturing industry. Technol. Forecast. Soc. Chang. 2010, 77, 803-815. [CrossRef]

27. Zhu, K.; Kraemer, K.L.; Xu, S. The process of innovation assimilation by firms in different countries: A technology diffusion perspective on e-business. Manag. Sci. 2006, 52, 1557-1576. [CrossRef]

28. Alkhalil, A.; Sahandi, R.; John, D. An exploration of the determinants for decision to migrate existing resources to cloud computing using an integrated TOE-DOI model. J. Cloud Comput. 2017, 6, 2. [CrossRef]

29. Arpaci, I.; Yardimci, Y.C.; Ozkan, S.; Turetken, O. Organizational adoption of information technologies: A literature review. Int. J. eBusiness eGovernment Stud. 2012, 4, 37-50.

30. Thong, J.Y. An integrated model of information systems adoption in small businesses. J. Manag. Inf. Syst. 1999, 15, 187-214. [CrossRef]

31. Rogers, E. Diffusion of Innovations, 5th ed.; Free Press: New York, NY, USA, 2003.

32. Yin, R.K. Case Study Research: Design and Methods; Applied Social Research Methods Series, 5; SAGE Publications: London, UK, 1994.

33. Yin, R.K. The case study as a serious research strategy. Knowledge 1981, 3, 97-114. [CrossRef]

34. Eisenhardt, K.M. Building theories from case study research. Acad. Manag. Rev. 1989, 14, 532-550. [CrossRef]

35. Leonard-Barton, D. A Dual Methodology for Case Studies: Synergistic Use of a Longitudinal Single Site with Replicated Multiple Sites. Organ. Sci. 1990, 1, 248-266. [CrossRef]

36. Henry, N.; Pinch, S. Spatialising knowledge: Placing the knowledge community of Motor Sport Valley. Geoforum 2000, 31, 191-208. [CrossRef]

37. Bell, E.; Bryman, A. The ethics of management research: An exploratory content analysis. Br. J. Manag. 2007, 18, 63-77. [CrossRef]

38. Baker, J. The technology-organization-environment framework. In Information Systems Theory: Explaining and Predicting Our Digital Society; Dwivedi, K.Y., Wade, R.M., Schneberger, L.S., Eds.; Springer: New York, NY, USA, 2012; Volume 1, pp. $231-245$. [CrossRef]

39. Ruan, Y.; Hang, C.C.; Wang, Y.M. Government's role in disruptive innovation and industry emergence: The case of the electric bike in China. Technovation 2014, 34, 785-796. [CrossRef]

40. FIA WEC. FIA World Endurance Championship Classes. Available online: http://www.fiawec.com/presentation/classes.html (accessed on 24 October 2016).

41. Beck-Burridge, M.; Walton, J. A world beyond grand prix. In Britain's Winning Formula; Springer: Berlin/Heidelberg, Germany, 2000; pp. 43-58.

42. Zapata, C.; Nieuwenhuis, P. Exploring innovation in the automotive industry: New technologies for cleaner cars. J. Clean. Prod. 2010, 18, 14-20. [CrossRef]

43. Smith, R. Alpine E Renault: The Sports Prototypes 1963 to 1969; Veloce Publishing Ltd.: Poundbury, UK, 2010.

44. Revealed: The \$2.6 Billion Budget That Fuels F1's 10 Teams. Available online: https://www.forbes.com/sites/csylt/2018/04/08 / revealed-the-2-6-billion-budget-that-fuels-f1s-ten-teams/\#14558d966595 (accessed on 26 April 2019).

45. Christensen, C. The Innovator's Dilemma: When New Technologies Cause Great Firms to Fail; Harvard Business Review Press: Boston, MA, USA, 2013.

46. Smith, D.J. Technological discontinuities, outsiders and social capital: A case study from Formula 1. Eur. J. Innov. Manag. 2012, 15, 332-350. [CrossRef]

47. Foxall, G.R.; Johnston, B.R. Innovation in Grand Prix motor racing: The evolution of technology, organization and strategy. Technovation 1991, 11, 387-402. [CrossRef]

48. Jenkins, M. Technological Discontinuities and Competitive Advantage: A Historical Perspective on Formula 1 Motor Racing 1950-2006. J. Manag. Stud. 2010, 47, 884-910. [CrossRef]

49. Mastromarco, C.; Runkel, M. Rule changes and competitive balance in Formula One motor racing. Appl. Econ. 2009, 41, 3003-3014. [CrossRef]

50. Papachristos, G. Technology, performance and team adaptation to regulation in Formula 1. In Proceedings of the 32nd International Conference of the System Dynamics Society, Delft, The Netherlands, 20-24 July 2014.

51. Smith, R. Alpine E Renault: The Development of the Revolutionary Turbo F1 Car 1968-1979; Veloce Publishing: Dorset, UK, 2008.

52. Mansfield, E. Industrial Research and Technological Innovation; An Econometric Analysis; W.W. Norton: New York, NY, USA, 1968.

53. Hill, C.W.; Rothaermel, F.T. The performance of incumbent firms in the face of radical technological innovation. Acad. Manag. Rev. 2003, 28, 257-274. [CrossRef]

54. Wright, P.; Matthews, T. Formula 1 Technology; SAE: Warrendale, PA, USA, 2001.

55. Banbury, C.M.; Mitchell, W. The effect of introducing important incremental innovations on market share and business survival. Strateg. Manag. J. 1995, 16, 161-182. [CrossRef]

56. Dahlander, L.; Gann, D.M. How open is innovation? Res. Policy 2010, 39, 699-709. [CrossRef]

57. Hofstetter, R.; Zhang, J.Z.; Herrmann, A. Successive open innovation contests and incentives: Winner-take-all or multiple prizes? J. Prod. Innov. Manag. 2018, 35, 492-517. [CrossRef]

58. Huizingh, E.K.R.E. Open innovation: State of the art and future perspectives. Technovation 2011, 31, 2-9. [CrossRef] 
59. Chesbrough, H. Open innovation: A new paradigm for understanding industrial innovation. Open Innov. Res. A New Paradig. 2006, 400, 1-19.

60. Spender, J.-C.; Corvello, V.; Grimaldi, M.; Rippa, P. Startups and open innovation: A review of the literature. Eur. J. Innov. Manag. 2017, 20, 4-30. [CrossRef]

61. Hervas-Oliver, J.-L.; Sempere-Ripoll, F.; Boronat-Moll, C. Technological innovation typologies and open innovation in SMEs: Beyond internal and external sources of knowledge. Technol. Forecast. Soc. Chang. 2021, 162, 120338. [CrossRef]

62. Gianiodis, P.T.; Ellis, S.C.; Secchi, E. Advancing a typology of open innovation. Int. J. Innov. Manag. 2010, 14, 531-572. [CrossRef]

63. Bogers, M.; Chesbrough, H.; Heaton, S.; Teece, D.J. Strategic Management of Open Innovation: A Dynamic Capabilities Perspective. Calif. Manag. Rev. 2019, 62, 77-94. [CrossRef] 